\title{
Optimizing 128 Slice Spiral CT Scanner Parameters to Minimize Acquisition Errors
}

\author{
Authors
}

\author{
Santosh Kumar Malyala ${ }^{1}$,Ravi Kumar. $Y^{2}$
}

Department of Mechanical Engineering, National Institute of Technology Warangal,Telangana - 506004,

INDIA

\begin{abstract}
Additive Manufacturing(AM) is the most advanced manufacturing process in case of medical and dental industry. Computed Tomography (CT) or Magnetic Resonance Imaging(MRI) images are the primary source to fabricate the medical models. CT scan data is stored in the form of Digital Imaging and Communication in Medicine (DICOM) format. Multi slice Spiral CT scanners are effective in capturing maximum data of human anatomy in minimum time. In processing of CT image acquisition some of parameters like tube current, tube voltage and pitch play a major role. The aim of this work is to reduce the radiation dose, minimize dimensional and volumetric error by identifying the optimal input parameters. Considered three CT parameters with three levels to conduct the experiments.AL9 orthogonal array and $S / N$ (Signal by Noise) ratio is used to analyze the CT acquisition data. The observation from the work is that the tube voltage is majorly responsible in case of resulting higher radiation dose, which has been minimized from 65.64 to $20.64 \mathrm{mGy}$.Dimensional and volumetric errors have been reduced from 1.31 to $0.78 \mathrm{~mm}$ and 57188.91 to $12933.26 \mathrm{~mm}^{3}$ respectively.
\end{abstract}

Key words: Additive Manufacturing, Computed Tomography, Image Acquisition, CT parameters, Radiation dose.

\section{INTRODUCTION:}

Additive Manufacturing (AM) is promising technology in current days. This technology initially started as Rapid Prototyping(RP)in the 1980's. This technology made a revolutionary change in creating physical models out of Computer Aided Design (CAD) systems. Medical scanning systems such as CT or MRI and any Reverse Engineering (RE) techniques [1]. AM is capable of making physical models from any kind of 3-Dimensional (3D)data. In process of printing physical model AM follows layer by layer fabrication process, which is exactly opposite way of conventional subtractive manufacturing process [2]. This technology became popular and most successful in fabrication of prototypes within less time. Later on this technology entered in to all most all the industries such as Automobile, Aerospace, Medical, Dental, Jewelry, Construction and many more [3]. From the early 2000 's AM has grown very strong in case of medical and dental applications. It is very quick and easy process to replicate physical model of desired body part of patient, which is almost impossible through conventional way of approach [4]. These medical models help in case of designing customized implants or prosthesis to the patients and preplanning of complex surgeries to the surgeons [5].

Each and every AM technique follows almost a standard sequence of steps to make physical model out of digital data. The basic step is to convert any input source to standard Stereolithography(STL) format, which is globally accepted by all AM machines. Initially data may be from native CAD systems or from DICOM images of CT or MRI but all of these have to finally convert into STL file only [6]. To acquire DICOM patient has to undergo for the CT scan which causes radiation dose to the patient. Even though this is known fact to the patient, radiologist and surgeon that $\mathrm{CT}$ scan effect causes 
radiation dose to the patient which harmful to the patient and unfortunately there is no other alternative to get patient scan data till today.

Several researchers are working on increasing image quality and reducing the radiation dose in medical CT scanner. Hausleiter et al proposed a study to evaluate image quality and radiation dose using a100 $\mathrm{kVp}$ tube voltage scan protocol compared with standard $120 \mathrm{kVp}$ for coronary computed tomography angiography (CTA) [7]. Hiller et al presented a computer simulation platform, which is able to investigate error sources in dimensional CT measurements. This method has the potential to deal with all kinds of systematic and random errors that influence a dimensional CT measurement. A case study demonstrates the practical application of the VCT simulator using numerically generated CT data and statistical evaluation methods [8].Waaijer et al described to prospectively assess the effects of lower tube voltage and various effective tube currents on image quality for CT angiography of the circle of Willis [9]. Tang et al investigated the effect of low tube voltage $(80 \mathrm{kV})$ on image quality, radiation dose, and low-contrast detectability (LCD) in CT [10].Nakayama et al compared aortic CT angiography performed at a low tube voltage and reduced dose of contrast material with standard-voltage, standard contrastdose CT angiography [11].Aim of current work is to minimize radiation dose, volumetric and dimensional errors, while simultaneously increasing the DICOM quality by analyzing various $\mathrm{CT}$ acquisition parameters.

\section{METHODOLOGY:}

\section{Phantom Description:}

In the current study an adult dry skull is considered for experimentation on the CT scanner. This phantom is taken from an adult male dead body which is aged 35, shown in the Figure 1. The phantom has been undergone for all the medical cleaning process before experimentation. The phantom used for experimentation is procured from Pennainea Dental College of Medical Science, Hyderabad, India.

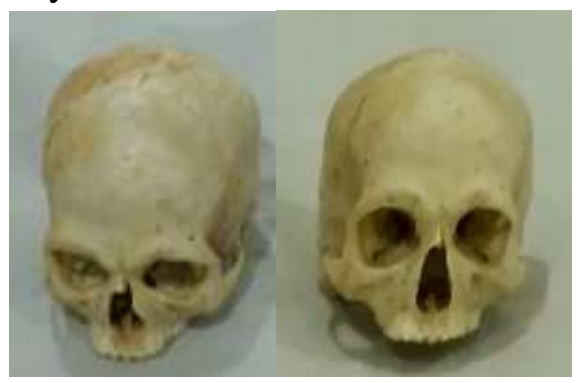

Figure1. Dry skull phantom

\section{CT Set-up:}

The dry skull has undergone scanning for 15times with 128 slice spiral CT scanner(Siemes Somata Perspective No: 76970).The experimentation work has been conducted at Ozone Hospitals, Hyderabad, India. The series of experiments were conducted to improve the quality of image acquisition compared to the default settings of the scanner. The major input parameters that influence the scanning result are tube current, tube voltage and pitch. From the literature study the impact of tube voltage and tube current on radiation dose are maximum. The dry skull scanned four times to identify the interaction between tube current and tube voltage. The experimental parameters are shown in Table 1.From the experimentation results there is no interaction between the tube voltage and tube current for considered range (tube voltage from 80 to 130 and tube current from 50 to 300 ).

\section{Table 1 CT parameters for identify the interaction}

\begin{tabular}{|l|l|l|}
\hline $\begin{array}{l}\text { Experiment } \\
\text { Number }\end{array}$ & $\begin{array}{l}\text { Tube Voltage } \\
(\mathrm{kV})\end{array}$ & $\begin{array}{l}\text { Tube Current } \\
(\mathrm{mA})\end{array}$ \\
\hline 1 & 80 & 50 \\
\hline 2 & 130 & 50 \\
\hline 3 & 80 & 300 \\
\hline 4 & 130 & 300 \\
\hline
\end{tabular}

After analyzing the results there is no interaction between tube current and voltage (in the limits where experimentation is conducted).After the basic investigation identified three parameters with three levels, which are shown in Table 2. 
Table 2 CT Scanner acquisition parameters

\begin{tabular}{|l|l|l|l|}
\hline \multirow{2}{*}{} & \multicolumn{3}{|l|}{ Level of Parameter } \\
\cline { 2 - 4 } & 1 & 2 & 3 \\
\hline Tube voltage (kV) & 80 & 110 & 130 \\
\hline Tube current (mA) & 50 & 175 & 300 \\
\hline $\begin{array}{l}\text { Pitch (table } \\
\text { movement/slice } \\
\text { thickness) }\end{array}$ & 0.5 & 0.75 & 1 \\
\hline
\end{tabular}

The initial scan was done under default parameters, which are Tube current of $270 \mathrm{~mA}$, Tube voltage of $130 \mathrm{kV}$ and a pitch of 0.5 . The result from this scan is used as a reference to improve the accuracy of the scan data. These default parameters were defined by the software which was pre-installed in the CT scanner. For experimentation considered three parameters with three levels, total possible combinations for this are 27 experiments. Based on L9 orthogonal array nine scans were conducted with various tube voltage, tube current and pitch, the experimental design is shown in Table 3 . The CT scans were done to find the optimized parameters.

\section{Table 3L9orthogonal array for} experimentation

\begin{tabular}{|l|l|l|l|l|}
\hline S.No & $\begin{array}{l}\text { Experiment } \\
\text { Number }\end{array}$ & $\begin{array}{l}\text { Tube Voltage } \\
(\mathrm{kV})\end{array}$ & $\begin{array}{l}\text { Tube Current } \\
(\mathrm{mA})\end{array}$ & Pitch \\
\hline 1 & Exp. No. 1 & 80 & 50 & 0.5 \\
\hline 2 & Exp. No. 2 & 80 & 175 & 0.75 \\
\hline 3 & Exp. No. 3 & 80 & 300 & 1 \\
\hline 4 & Exp. No. 4 & 110 & 50 & 0.5 \\
\hline 5 & Exp. No. 5 & 110 & 175 & 0.75 \\
\hline 6 & Exp. No. 6 & 110 & 300 & 1 \\
\hline 7 & Exp. No. 7 & 130 & 50 & 0.5 \\
\hline 8 & Exp. No. 8 & 130 & 175 & 0.75 \\
\hline 9 & Exp. No. 9 & 130 & 300 & 1 \\
\hline
\end{tabular}

\section{Dimensional Error:}

Nine experiments were conducted and results from these nine experiments were analyzed to find out the optimum parameters for the final experimentation. These results were analyzed in the CAD with help of MIMICS 18.0 software to identify the error between scanned CT data and dry skull [12].In dry skull 15landmark points were identified. Based on these15 landmarks points9 linear measurements are identified, which are
1 Minimum frontal breadth Distance between the two frontotemporale ( $\mathrm{ft}$ )

2 Biorbital breadth Distance between right and left ectoconchion (ec)

3 Bizygomatic diameter Distance between most lateral points on the zygomatic arches

4 Nasal breadth Maximum breadth of the nasal aperture

5 Orbital height Distance between the superior and inferior orbital margins

6 Foramen magnum breadth Distance between the lateral margins of foramen magnum at the points of greatest lateral curvature

7 Foramen magnum length Distance from basion (ba) to opisthion (o)

8 Foramen ovale Distance between left and right of foramen ovale

9 Foramen spinosum Distance between left and right of foramen spinosum

shown in Table 4[13]. The landmark points and linear measurements were shown in the Figure 2.

\section{Table 4Linear measurements}

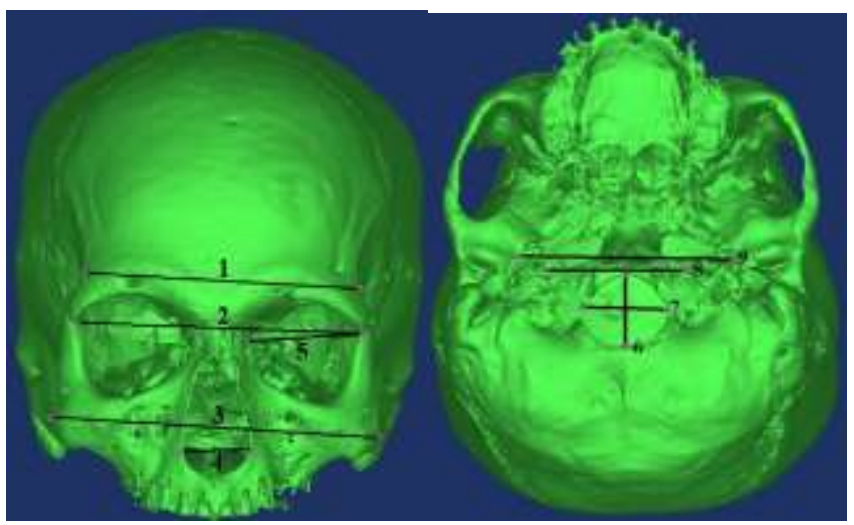

Figure 2. Dry skull linear measurements

Nine similar measurements were measured on each CAD model and then compared with the manual measurements made with digital vernier calipers on the dry skull. The measurements for 3D CAD model are measured using MIMICS 18.0 software with the precision of third decimal place to get the accurate measurements. Each and every measurement has measured twice to get exact measurements. All the measurements were tabulated in the Table 5. The difference between the manual measurements to the CAD is considered as the dimensional error. 
Dimensional error $=$ Dry skull measured dimension - 3D CAD Skull measured dimension.

Table 5 Dimensional measurements of dry skull and CAD models

\begin{tabular}{|c|c|c|c|c|c|c|c|c|c|c|}
\hline \multicolumn{2}{|c|}{ Measurement Number } & $\begin{array}{l}1 \\
(\mathrm{~mm})\end{array}$ & $\begin{array}{l}2 \\
(\mathrm{~mm})\end{array}$ & $\begin{array}{l}3 \\
(\mathrm{~mm})\end{array}$ & $\begin{array}{l}4 \\
(\mathrm{~mm})\end{array}$ & $\begin{array}{l}5 \\
(\mathrm{~mm})\end{array}$ & $\begin{array}{l}6 \\
(\mathrm{~mm})\end{array}$ & $\begin{array}{l}7 \\
(\mathrm{~mm})\end{array}$ & $\begin{array}{l}8 \\
(\mathrm{~mm})\end{array}$ & $\begin{array}{l}9 \\
(\mathrm{~mm})\end{array}$ \\
\hline \multicolumn{2}{|l|}{ Dry skull } & 99.21 & 99.62 & 114.53 & 21.84 & 38.99 & 30.73 & 32.77 & 47.47 & 76.03 \\
\hline \multirow[t]{2}{*}{ Exp. No. 1} & CAD Model & 97.41 & 98.16 & 113.46 & 21.39 & 37.26 & 29.83 & 31.57 & 46.98 & 73.14 \\
\hline & Dimensional Error & 1.8 & 1.46 & 1.07 & 0.45 & 1.73 & 0.9 & 1.2 & 0.49 & 2.89 \\
\hline \multirow[t]{2}{*}{ Exp. No. 2} & CAD Model & 97.12 & 97.47 & 113.57 & 21.47 & 36.08 & 29.78 & 31.61 & 46.18 & 73.56 \\
\hline & Dimensional Error & 2.09 & 2.15 & 0.96 & 0.37 & 2.91 & 0.95 & 1.16 & 1.29 & 2.47 \\
\hline \multirow[t]{2}{*}{ Exp. No. 3} & CAD Model & 97.5 & 97.97 & 113.44 & 21.53 & 37.04 & 29.91 & 31.81 & 46.35 & 74.47 \\
\hline & Dimensional Error & 1.71 & 1.65 & 1.09 & 0.31 & 1.95 & 0.82 & 0.96 & 1.12 & 1.56 \\
\hline \multirow[t]{2}{*}{ Exp. No. 4} & CAD Model & 97.31 & 97.83 & 113.49 & 21.48 & 36.35 & 30.12 & 31.86 & 46.83 & 75.17 \\
\hline & Dimensional Error & 1.9 & 1.79 & 1.04 & 0.36 & 2.64 & 0.61 & 0.91 & 0.64 & 0.86 \\
\hline \multirow[t]{2}{*}{ Exp. No. 5} & CAD Model & 97.46 & 98.17 & 113.41 & 21.63 & 36.86 & 29.82 & 32.05 & 46.47 & 73.94 \\
\hline & Dimensional Error & 1.75 & 1.45 & 1.12 & 0.21 & 2.13 & 0.91 & 0.72 & 1 & 2.09 \\
\hline \multirow[t]{2}{*}{ Exp. No. 6} & CAD Model & 97.49 & 97.7 & 113.21 & 21.36 & 37.21 & 29.93 & 31.78 & 46.62 & 73.82 \\
\hline & Dimensional Error & 1.72 & 1.92 & 1.32 & 0.48 & 1.78 & 0.8 & 0.99 & 0.85 & 2.21 \\
\hline \multirow[t]{2}{*}{ Exp. No. 7} & CAD Models & 97.23 & 98.14 & 113.6 & 21.58 & 37.2 & 30.08 & 31.85 & 46.39 & 74.39 \\
\hline & Dimensional Error & 1.98 & 1.48 & 0.93 & 0.26 & 1.79 & 0.65 & 0.92 & 1.08 & 1.64 \\
\hline \multirow[t]{2}{*}{ Exp. No. 8} & CAD Model & 97.29 & 97.67 & 113.58 & 21.48 & 36.93 & 29.99 & 31.88 & 45.89 & 73.79 \\
\hline & Dimensional Error & 1.92 & 1.95 & 0.95 & 0.36 & 2.06 & 0.74 & 0.89 & 1.58 & 2.24 \\
\hline \multirow[t]{2}{*}{ Exp. No. 9} & CAD Model & 97.11 & 97.83 & 113.27 & 21.46 & 37.03 & 29.96 & 31.87 & 46.83 & 74.27 \\
\hline & Dimensional Error & 2.1 & 1.79 & 1.26 & 0.38 & 1.96 & 0.77 & 0.9 & 0.64 & 1.76 \\
\hline
\end{tabular}

\section{VOLUMETRIC ERROR:}

The volume for the dry skull is measured using water displacement technique. In this the skull is immersed in to the beaker of water, where the initial water level was noted and final reading is taken after the rise in water level (after immersion of skull). The difference in water levels of these two readings gives the volume of dry skull, which is shown in Figure 3.

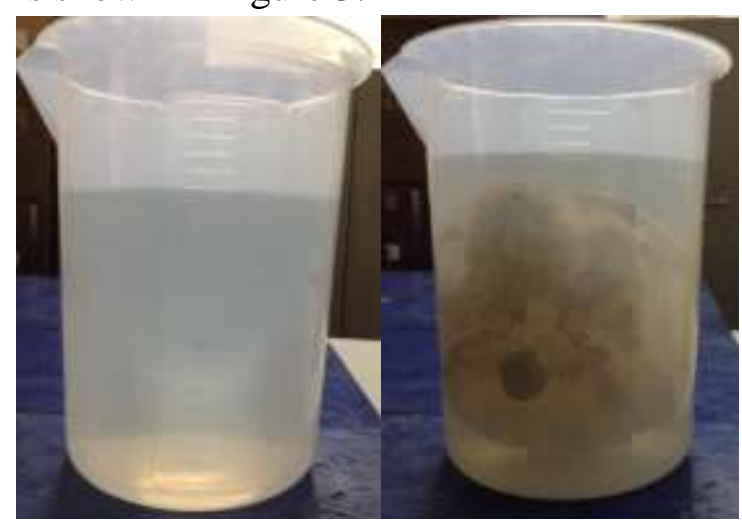

Figure 3 Volume measurement with water displacement technique

The Volume for 3D CAD model is measured using MIMICS 18.0 software. To maintain consistency all the volumes were calculated in cubic millimeters $\left(\mathrm{mm}^{3}\right)$. The difference in volume from water displacement measurement to $3 \mathrm{D}$ CAD measurement is considered as the volumetric error and same procedure is considered for set of experiments. The readings for the same are tabulated in the Table 6 .

Table 6 Volume measurement of dry mandible and CAD model

\begin{tabular}{|l|l|l|}
\hline Volume taken from & Volume $\left(\mathrm{mm}^{3}\right)$ \\
\hline Dry skull & CAD Model & 449800 \\
\hline \multirow{3}{*}{ Exp. No. 1 } & Volumetric Error & 439805.55 \\
\hline \multirow{2}{*}{ Exp. No. 2 } & CAD Model & 9994.5 \\
\cline { 2 - 3 } & Volumetric Error & 440044.34 \\
\hline \multirow{3}{*}{ Exp. No. 4} & CAD Model & 9755.7 \\
\cline { 2 - 3 } & Volumetric Error & 440249.02 \\
\hline \multirow{3}{*}{ Exp. No. 5 } & CAD Model & 9551.0 \\
\cline { 2 - 3 } & Volumetric Error & 407512.14 \\
\hline \multirow{3}{*}{ Exp. No. 6 } & CAD Model & 42287.9 \\
\cline { 2 - 3 } & Volumetric Error & 411604.76 \\
\hline \multirow{2}{*}{ Exp. No. 8} & CAD Model & 38195.2 \\
\cline { 2 - 3 } & Volumetric Error & 409593.69 \\
\cline { 2 - 3 } & CAD Model & 40206.3 \\
\cline { 2 - 3 } & Volumetric Error & 393018.02 \\
\hline \multirow{2}{*}{ Exp. No. 9 } & CAD Model & 56782.0 \\
\cline { 2 - 3 } & Volumetric Error & 395014.06 \\
\cline { 2 - 3 } & CAD Model & 54785.9 \\
\cline { 2 - 3 } & Volumetric Error & 536189.86 \\
\hline
\end{tabular}




\section{RADIATION DOSE:}

All the CT scanners cause radiation to the patient while undergoing the scanning. It is harmful to the patient, but as per the current technology there is no other alternative to get scanned without radiation dose. The emitted radiation levels my change from the scanner to scanner. The effect of radiation dose majorly depends on the tube voltage, tube current and pitch applied at the time of scanning [14]. The value of these parameters depends on the scanned anatomy or which body part is going to be scanned. But still there is a chance to reduce radiation dose by optimizing the input parameters. The radiation dose values for the conducted experiments are tabulated in the Table 7.

\section{Table7. Radiation dose for each experiment}

\section{STATISTICAL ANALYSIS:}

One of the commonly used and successful methods for engineering analysis that consists of series of experiments is Taguchi. Taguchi is used to conduct set of experiments in a controlled way [15]. This technique not only minimizes the number of experiments but also saves lot of effort and time in obtaining results. In the current study Taguchi is used to define values to be conducted in the experimentation for tube voltage, tube current and pitch in the other hand to minimize various parameters like radiation dose, volumetric

\begin{tabular}{|l|l|}
\hline $\begin{array}{l}\text { Experiment } \\
\text { Number }\end{array}$ & $\begin{array}{l}\text { Radiation } \\
\text { Dose (mGy) }\end{array}$ \\
\hline Exp. No. 1 & 3.44 \\
\hline Exp. No. 2 & 12.11 \\
\hline Exp. No. 3 & 20.64 \\
\hline Exp. No. 4 & 8.56 \\
\hline Exp. No. 5 & 29.57 \\
\hline Exp. No. 6 & 50.7 \\
\hline Exp. No. 7 & 12.16 \\
\hline Exp. No. 8 & 45.8 \\
\hline Exp. No. 9 & 72.96 \\
\hline
\end{tabular}

and dimensional errors. Obtained results from the experiments are analyzed and the significant factors were identified.

\section{RESULTS:}

To find the interaction between tube voltage and tube current with respect to the radiation dose, dimensional \& volumetric errors calculation is done by using experimental design as shown in Table 1. Results for the interaction between tube voltage and tube current are shown in Table 8.

Table 8 Interaction results

\begin{tabular}{|l|l|l|l|l|l|l|}
\hline Exp No & Input Parameters & \multicolumn{3}{l|}{ Output Parameters } \\
\cline { 2 - 7 } & $\begin{array}{l}\text { Tube } \\
\text { Voltage }(\mathrm{kV})\end{array}$ & $\begin{array}{l}\text { Tube } \\
\text { current(mA) }\end{array}$ & Pitch & $\begin{array}{l}\text { CT Dose } \\
(\mathrm{mGy})\end{array}$ & $\begin{array}{l}\text { Dim- } \\
\text { Error } \\
(\mathrm{mm})\end{array}$ & $\begin{array}{l}\text { Volumetric } \\
\text { Error } \\
(\mathrm{mm} 3)\end{array}$ \\
\hline 1 & 130 & 50 & 0.55 & 12.33 & 1.11 & 10838.23 \\
\hline 2 & 130 & 300 & 0.55 & 72.68 & 0.94 & 10620.07 \\
\hline 3 & 80 & 50 & 0.55 & 3.49 & 1.28 & -33234.97 \\
\hline 4 & 80 & 300 & 0.55 & 20.56 & 1.50 & -32944.95 \\
\hline
\end{tabular}


The average value for each experiment is considered as the dimensional error for that particular experiment. The volumetric error is calculated separately for each experiment(3D CAD model) using the MIMICS 18.0 software. Radiation dose is identified from the CT scan data
(Radiation dose is calculated by CT scanner at the time of scanning the dry skull and displays once after the scanning completes, recorded for each experiment). Theseradiation dose, dimensional and volumetric errors are tabulated in the Table 9.

Table 9 Dimensional and volumetric errors

\begin{tabular}{|c|c|c|c|c|}
\hline $\begin{array}{l}\text { Experiment } \\
\text { Number }\end{array}$ & $\begin{array}{l}\text { CT Dose } \\
(\mathrm{mGy})\end{array}$ & $\begin{array}{l}\text { Dimensional } \\
\text { Error }(\mathrm{mm})\end{array}$ & $\begin{array}{l}\text { Volumetric } \\
\text { Error }\left(\mathrm{mm}^{3}\right)\end{array}$ & $\begin{array}{l}\mathrm{S} / \mathrm{N} \\
\text { ratio }\end{array}$ \\
\hline Exp. No. 1 & 3.44 & 1.33222 & 9994.5 & -75.224 \\
\hline Exp. No. 2 & 12.11 & 1.59444 & 9755.7 & $\begin{array}{l}- \\
75.0139\end{array}$ \\
\hline Exp. No. 3 & 20.64 & 1.24111 & 9551.0 & $\begin{array}{l}- \\
74.8298\end{array}$ \\
\hline Exp. No. 4 & 8.56 & 1.19444 & 42287.9 & $\begin{array}{l}- \\
87.7531\end{array}$ \\
\hline Exp. No. 5 & 29.57 & 1.26444 & 38195.2 & $\begin{array}{l}- \\
86.8690\end{array}$ \\
\hline Exp. No. 6 & 50.70 & 1.34111 & 40206.3 & $\begin{array}{l}- \\
87.3147\end{array}$ \\
\hline Exp. No. 7 & 12.16 & 1.19222 & 56782.0 & $\begin{array}{l}- \\
90.3130\end{array}$ \\
\hline Exp. No. 8 & 45.80 & 1.41000 & 54785.9 & $\begin{array}{l}- \\
90.0022\end{array}$ \\
\hline Exp. No. 9 & 72.96 & 1.28444 & 53610.1 & $\begin{array}{l}- \\
89.8137\end{array}$ \\
\hline
\end{tabular}

Taguchi statistical method is used to find optimized CT parameters with calculation of $\mathrm{S} / \mathrm{N}$ ratios for each experiment. Here smaller- thebetter principle is applied, since the objective of work is to minimize the radiation dose, volumetric and dimensional errors. $\mathrm{S} / \mathrm{N}$ ratio is calculated by sing the below formulae [16]:

$$
\frac{S}{N}=-10 \log _{10} \frac{1}{n}\left(\sum_{i=0}^{i=n} y_{i}^{2}\right)
$$

Where $\mathrm{n}=$ measurements made in a row or trial, $\mathrm{y}$ $=$ measurement value in a row or run.

For the acquired $\mathrm{CT}$ images $\mathrm{S} / \mathrm{N}$ ratio of mean were calculated at each level and tabulated in the Table 9. Minitab software is used to analyze and draw the graphs for effect of radiation dose, volumetric and dimensional error of $\mathrm{S} / \mathrm{N}$ ratio to obtain optimized values, which are shown in Figure 4. With help of this the optimal CT parameters are identified as Tube voltage $80 \mathrm{kV}$, tube current $300 \mathrm{~mA}$ and pitch as 1 .

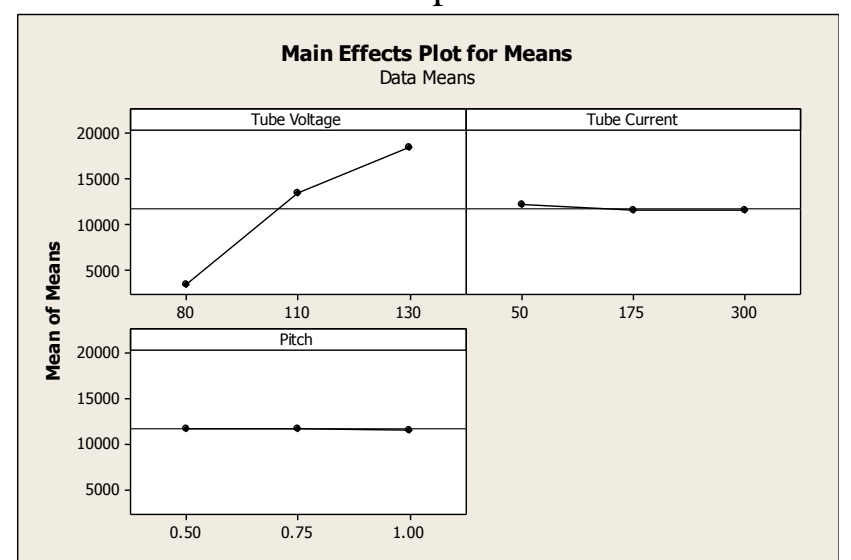

Figure 4 Effect of process parameters on radiation dose, dimensional and volumetric errors 
ANOVA results for Dimensional and volumetric errors are tabulated in table 10. All the experimentation analysis is carried with $1 \%$ of significance that is with $99 \%$ level of confidence. The analysis of ANOVA is to identify the characteristics of CT acquisition parameters.Based on ANOVA analysis the tube voltage has the major significance in parameters of $\mathrm{CT}$ at image acquisition step.

Table 10 Response table for $\mathrm{S} / \mathrm{N}$ ratios of $\mathrm{CT}$ image acquisition

\begin{tabular}{|l|l|l|l|}
\hline Level & $\begin{array}{l}\text { Tube } \\
\text { voltage } \\
(\mathrm{kV})\end{array}$ & $\begin{array}{l}\text { Tube } \\
\text { current } \\
(\mathrm{mA})\end{array}$ & Pitch \\
\hline 1 & -75.02 & -84.43 & $\begin{array}{l}- \\
84.18\end{array}$ \\
\hline 2 & -87.31 & -83.96 & $\begin{array}{l}- \\
84.19\end{array}$ \\
\hline 3 & -90.04 & -83.99 & $\begin{array}{l}- \\
84.00\end{array}$ \\
\hline Delta & 15.02 & 0.47 & 0.19 \\
\hline Rank & 1 & 2 & 3 \\
\hline
\end{tabular}

To quantitatively analyze the improvement or optimization of parameters, a CT scan was performed with the optimal parameters obtained from the above result. Same 9 linear measurements with 15 landmarks were measured and these measurements are compared with the linear measurements conducted with default CT parameters. The results with both default and optimal parameters are shown in the Table 11.

Table 11Comparison of default scanner parameters, optimized parameters and their result

\begin{tabular}{|l|l|l|}
\hline & $\begin{array}{l}\text { Default } \\
\text { Parameters }\end{array}$ & $\begin{array}{l}\text { Optimized } \\
\text { Parameters }\end{array}$ \\
\hline Tube Voltage(kV) & 130 & 80 \\
\hline Tube Current(mA) & 270 & 300 \\
\hline Pitch & 0.5 & 1 \\
\hline $\begin{array}{l}\text { Dimensional Error } \\
(\mathrm{mm})\end{array}$ & 1.31 & 0.78 \\
\hline $\begin{array}{l}\text { Volumetric Error } \\
\left(\mathrm{mm}^{3}\right)\end{array}$ & 57188.91 & 12933.26 \\
\hline CT Dose(mGy) & \multicolumn{1}{|c|}{65.64} & 20.64 \\
\hline
\end{tabular}

\section{CONCLUSION}

In the current work, initially the scanning was done with the default parameters of the CT scanner(on which all the scanning's were done for the paper). In the next step found that there is no interaction between the tube current and tube voltage for the considered CT scanner. An L9orthogonal array has identified to conduct the experiments to identify the optimal CT scanner parameters for the scanning of Skull. Final CT scan for the skull has been conducted under optimal parameters and compared results with the default CT scanned data. From the work it can be concluded that with optimal CT scan parameters the radiation dose has been reduced $68.5 \%$, dimensional and volumetric errors also reduced $40.4 \%$ and $77.3 \%$ respectively. This experimental design and optimized method provided minimal data loss compared to default setting parameters. This method is applicable for scanning of any other human anatomy or to other CT scanner. The procedure remains same but the values may differ. In future there is a scope to find global default CT parameters for all the anatomy or CT scanners.

Acknowledgments:

I would like to thank Science and Engineering Research Board (SERB, Department of Science and Technology (DST)) for financial support with a wide reference of : NO: DST/SERB/SB/S3/MMER/0037/2013.

\section{REFERENCES}

1. Chua. C. K and Leong. K. F. Rapid Prototyping, Principles and Applications in Manufacturing, World Scientific, 2000.

2. ASTM F2792-12a, Standard Terminology for Additive Manufacturing Technologies, ASTM International, (West Conshohocken, PA, 2012)

3. T. T. Wohler, Additive Manufacturing and 3D Printing State of the Industry, Annual Worldwide Progress Report, (Wohlers Associates, Colorado, USA, 2013) 
4. Gebhardt. A, Rapid Prototyping, Hanser Gardner Publications, Inc., 2003.

5. Webb. P. A, "A review of rapid prototyping (RP) techniques in the medical and biomedical sector", 2000, vol 24, P.P 149153.

6. Gibson. I, Cheung. L. K, Chow S. P, Cheung. W. L, Beh. S. L, Savalani. M, Lee. S. H, "The use of rapid prototyping to assist medical applications", AssisesEuropeennes de PrototypageRapide, 2004, vol 14.

7. Hausleiter. J, Martinoff. S, Hadamitzky. M, Martuscelli. E, Pschierer. I, Feuchtner. G. M, Sanz. P. C, Czermak. B, Meyer. T. S, Hein. F, Bischoff. B, Kuse, M, Schomig, A, Achenbach, A, Image Quality and Radiation Exposure with a Low Tube Voltage Protocol for Coronary CT Angiography, 2010, vol 3, P.P 1114-1123.

8. Hiller. J, Reindl L. M, computer simulation platform for the estimation of measurement uncertainties in dimensional X-ray computed tomography, Measurement, 2012, vol 45, P.P 2166-2182.

9. Waaijer. A, Prokop. M, Velthuis. B. K, Bakker. C. J. G, Gerard A. P, Leeuwen. M. S. V, Circle of Willis at CTAngiography: Dose Reduction and Image QualityReducing Tube Voltage and Increasing Tube Current Settings, Radiology, Vol 242, P.P 832-839.

10. Tang. K, Wang. L, Li. R, Lin. J, Zheng. X and Cao. G, Effect of Low Tube Voltage on Image Quality, Radiation Dose, and LowContrast Detectability at Abdominal Multi detector CT: Phantom Study, Journal of Biomedicine and Biotechnology, 2012, P.P $1-6$.

11. Nakayama. Y, Awai. K, Funama. Y, Liu. D, Nakaura. T, Tamura. Y, Yamashita. Y, Lower Tube Voltage Reduces Contrast Material and Radiation Doses on 16-MDCT Aortography, American Journal of Roentgenology, 2006, vol187, P.P 490-497.
12. Materialise NV, Technologielaan 15, 3001 Leuven, Belgium. (www.materialise.com/mimics)

13. El-Katatny. I, Masood. S.H and Morsi. Y.S, Error analysis of FDM fabricated medical replicas, Rapid Prototyping Journal, 2010, vol 16, P.P 36-43.

14. Goo. H.W CT Radiation Dose Optimization and Estimation: an Update for Radiologists, Korean Journal of Radiology, 2012, vol 13, P.P 1-11.

15. Taguchi. G, Introduction to quality engineering, Asian Productivity Organization, 1990.

16. Sharma. N, Ahmad. S, Khan. Z. A, Siddiquee. A. N, Optimization of cutting parameters for surface roughness in turning, International journal of Advanced research in engineering and technology, 2012, vol 3, P.P 86-96. 